\title{
Rethinking the Americans with Disabilities Act's Insurance Safe Harbor
}

\author{
Valarie Blake \\ College of Law, West Virginia University, 101 Law School Drive, Morgantown, WV 26506-6130, USA; \\ valarie.blake@mail.wvu.edu
}

Received: 15 August 2017; Accepted: 1 November 2017; Published: 7 November 2017

\begin{abstract}
Despite the importance of access to healthcare for the disabled, the Americans with Disabilities Act (ADA) has made little inroads in reducing disability-based discrimination by health insurers in the United States. One reason is undoubtedly the ADA's insurance safe harbor, which explicitly permits insurers to discriminate on the basis of disability in health insurance so long as the differential treatment is supported by actuarial data and is not just intended to disadvantage the disabled. While the safe harbor's harms are somewhat limited by the advent of the Affordable Care Act (ACA), they are not entirely neutralized. This article argues that there are both practical and principled reasons for amending the ADA to remove the insurance safe harbor. Practically speaking, the ADA could prove a useful tool to challenge aspects of the ACA that place the disabled at a disadvantage, but the insurance safe harbor limits this reach in meaningful ways. From a more principled or philosophical lens, the insurance safe harbor is a law that perpetuates stigma against the disabled and that no longer reflects the views of American society. For these reasons, and many others, a rethinking of the ADA's insurance safe harbor is necessary and timely.
\end{abstract}

Keywords: disability rights; health reform; ADA; health insurance; access to healthcare for the disabled; disabled health disparities

\section{Introduction}

Access to healthcare is a necessary component of some disabled people's ability to lead meaningful lives. Some members of the disabled community may require frequent medical attention because of their impairments, while others may not be sick but may rely on devices or services that are available only through the healthcare system. ${ }^{1}$ Access to these services may help disabled people to work, attend school, or live independently. Yet, disabled people in the United States have historically encountered a healthcare financing system that limits their access to health care and is designed without their needs in mind. ${ }^{2}$

The Americans with Disabilities Act (ADA) ${ }^{3}$ is celebrated as comprehensive and wide-reaching legislation that targets disability-based discrimination in employment, government programs, places of public accommodation, and other settings. Yet, the ADA has made little inroads in reducing

1 For a depiction of common healthcare needs of the disabled, see Common Barriers to Participation Experience by People with Disabilities, Ctr. for Disease Control and Prevention (17 March 2016). While some disabled people can be characterized as unhealthy, others do not so closely meet this categorization. See (Wendell 2001, p. 17).

2 See (Crossley 2000, p. 78) (private insurers have "made it their business ... to make decisions regarding the availability and nature of benefits ... that could often be construed as discrimination on the basis of disability."); see also (Roberts 2012a) (insurers engage in "profit-maximizing strategies that systematically disadvantage people with histories of illness and chronic health conditions.")

3 Americans with Disabilities Act of 1990, 42 U.S.C. $\S \S 12101-12213$ (2012). 
disability-based discrimination in health insurance. ${ }^{4}$ One reason for this failing is undoubtedly the ADA's insurance safe harbor. ${ }^{5}$ This provision permits insurers to discriminate on the basis of disability in health insurance, for example, by charging higher premiums or denying coverage of certain services, so long as the differential treatment is supported by actuarial data and is not just intended to disadvantage the disabled. ${ }^{6}$ Stated more simply, the insurance safe harbor exempts many potentially discriminatory practices by health insurers from the scope of the ADA.

While the ADA's insurance safe harbor has often been critiqued for its negative impact on disabled people's lives, ${ }^{7}$ its harms are somewhat limited by the advent of the Affordable Care Act (ACA). The ACA essentially overrides the ADA's insurance safe harbor by prohibiting underwriting in premiums, benefits, and other areas on the basis of disability, along with a host of other characteristics like health status or gender. ${ }^{8}$ Yet, the harms of the safe harbor are not entirely neutralized, even after the ACA's many insurance reforms.

This article argues that there are both practical and principled reasons for amending the ADA to remove the insurance safe harbor. Practically speaking, with the safe harbor intact, the threat of health insurance discrimination looms over the disabled if the ACA is ever repealed or replaced. Additionally, although the ACA greatly helps the disabled, it is not a disability rights law. The ADA is a useful tool to challenge aspects of the ACA that place the disabled at a disadvantage, but the insurance safe harbor limits this reach in meaningful ways. From a more principled or philosophical lens, the insurance safe harbor perpetuates stigma against the disabled. Leaving it in place suggests that we as a society approve of differential treatment of the disabled in healthcare, a perspective that appears to be broadly changing across American society. For these reasons, and many others, a rethinking of the ADA's insurance safe harbor is necessary and timely.

In Part II, the topic of insurance discrimination against the disabled is briefly overviewed, along with the role of the ADA's safe harbor in perpetuating it. Part III argues both practical and principled reasons for amending the ADA to remove the insurance safe harbor. Part IV briefly proposes two potential pathways towards reform but ultimately suggests that further research will be necessary to consider the best approach to amending or altering the law and the ramifications of doing so.

\section{Discrimination against the Disabled in Health Insurance and Relevant Legal Protections}

Health insurance practices often make it difficult or impossible for disabled people to obtain adequate healthcare coverage that meets their needs, especially prior to the ACA. Despite the special importance of healthcare to the disabled community, the law has fallen woefully short in protecting disabled people from discrimination by health insurers.

\subsection{Challenges for Disabled Peoples' Access to Healthcare}

Access to healthcare is critical for some disabled people to function meaningfully in society. Some disabled people can be classified as being in poor health; they may need ongoing medical treatment and pharmaceutical interventions in order to maintain or improve their health. For example, persons disabled by HIV or cancer may be reliant, at least for a time, on the medical system. Other disabled people are not well categorized as sick, but they require assistive devices, like walkers

4 (Bagenstos 2004, p. 27) (stressing many shortcomings of the ADA with respect to challenging private insurance discrimination on the basis of disability).

42 U.S.C. $\S 12201$ (c) (2012).

Id.

See (Crossley 2000) (“despite the ADA's self-proclaimed purpose of providing 'a clear and comprehensive national mandate for the elimination of discrimination against individuals with disabilities', the statute as interpreted accepts, rather than eliminates, actuarially justified discrimination in health insurance. Congress's inclusion of the insurance safe harbor reflected a conscious decision not to disrupt traditional underwriting practices by insurers.") Also see (Manning 2000; Cole 2003).

8 For a discussion of how various provisions of the ACA help to protect disabled people's access to healthcare, see generally (Roberts 2012b). 
or wheelchairs, that are only accessible through the medical system. Lastly, disability can influence one's access to social determinants of good health, like stable and well-paying employment or safe and consistent housing. This can lead to health problems for some people with disabilities.

While access to healthcare can be critical for some disabled people, a claim that the disabled as a class are more expensive to insure is improper and over-general. The disability community is large and heterogeneous. Many disabled people are healthy and do not require frequent or complex medical services, and only a small portion of the population, disabled or not, represent the high consumers of healthcare. Such thinking takes into account assistive devices which do not necessarily have to be funded by the healthcare system. Even if some disabled people do have greater healthcare needs, it does not necessarily follow that they are taxing the healthcare system more; in fact, many of needs of the disabled are not adequately funded by insurance and the disabled frequently pay high out of pocket costs. ${ }^{9}$ Disability is improperly conflated with disease. An assumption that the disabled are costly to insure may reflect an implicit bias that the disabled are necessarily unhealthier, which may be a relic of a society that for so many years viewed disability as a medical, rather than a social problem (a concept that will be discussed further later in the paper).

Although disability is not indicative of disease, discrimination on the basis of disability is commonplace in healthcare financing. About half of the disabled receive public health insurance through Medicare, Medicaid, or another type of government plan. ${ }^{10}$ These programs cannot discriminate in who can access their plans, as they are typically legislatively mandated to cover certain populations. ${ }^{11}$ Yet these plans can still be imperfect from a disability perspective, whether because they contain elements of managed care, ${ }^{12}$ inadequate provider networks, ${ }^{13}$ or fail to cover uniquely important services for the disabled. ${ }^{14}$

Private insurers cover the remainder of the insured disabled community and are even less likely to accommodate disabled persons' needs, in part because they are market-based, using actuarial practices to predict and avoid paying out costly services. ${ }^{15}$ A long history preceded the ACA, in which disabled people were frequently excluded from plans altogether or were subject to higher premiums and annual and lifetime caps. ${ }^{16}$ Insurers also designed benefits in ways that were disadvantageous to the disabled, for example, by only offering services to people who could obtain specific measured improvements that exceeded the possible improvements for disabled patients. ${ }^{17}$ Critical devices like wheelchairs, auxiliary aids, or prosthetics were almost never covered or came with severe restrictions in terms of cost and quantity. ${ }^{18}$ In another example, insurers sometimes sought to cover benefits only in institutional settings, rather than to cover them in community and home based settings, until Olmstead vs. L.C., 527 U.S. 581 (1999) limited this practice. ${ }^{19}$ Protections for these many forms of health

9 Miller, supra note 9. Also see (Schoen et al. 2017) (for a description of the large out of pocket costs faced by Medicare beneficiaries).

10 See (Miller et al. 2014).

11 Medicare covers all individuals, regardless of health status or income, over the age of 65 . Medicaid covers people based on their income and other attributes such as disability, parental status, and age.

12 See (Roberts 2012b, p. 1993) (arguing that Medicaid managed care plans harm disabled people's health through "reduced consumer choice, and a limited ability to access specialists.")

13 Id., arguing that the unwillingness of providers to accept low-reimbursement Medicaid payments affects disabled people's access to care.

14 For a comprehensive overview of how disabled people in the Medicaid expansion population receive insufficient benefits, see (Linder et al. 2016).

15 Miller, supra note 9.

16 For a thorough depiction of the various strategies by which private insurers reduce services for the disabled, see (Rosenbaum 2007). Also see (Bagenstos 2004, pp. 26-35).

17 Id.

18 See (Bagenstos 2004, pp. 31-32) ("Insurers often invoke the "medical necessity" concept to refuse to pay for more advanced (and more functional) prostheses where less expensive (and less functional) prostheses are available. The same "medical necessity" issue often arises when individuals with mobility impairments seek reimbursements for wheelchairs.")

19 In Olmstead vs. L.C., the Supreme Court held that the ADA requires states to adequately fund community-based care to ensure that disabled people receive services in integrated settings. 
insurance discrimination varied in the private insurance market depending on whether the insurance was employer-sponsored, small group, or individual. For example, the Employee Retirement Income Security Act of 1974 (ERISA) prohibited health status based and disability-based discrimination by group plans, while small group and individual insurance plans were left unregulated. ${ }^{20}$

The overall poor fit between the needs of the disabled and the design of health insurance significantly burdens disabled people. The disabled frequently shoulder high out of pocket medical expenses and these costs may inhibit them from seeking timely medical care or place a greater financial burden on them as individuals. Moreover, the poor fit between disabled people and private insurance may force disabled people onto public insurance plans, making it difficult or impossible for them to be able to work. ${ }^{21}$ Ultimately, this and other challenges may lead them to suffer from higher than average rates of preventable disease, health disparities, and limited opportunities. ${ }^{22}$

\subsection{The Americans with Disability Act Insurance Safe Harbor}

Laws that protect against disability-based discrimination often do not go far enough in addressing discrimination in healthcare financing. The Rehabilitation Act of 1974 was the first major legislation to reach the issue of disability-based health insurance discrimination, but it only extends to entities that accept federal funding, like Medicaid, and these entities do not pose a great of threat with respect to health insurance discrimination. ${ }^{23}$ It took sixteen more years before private insurance discrimination was finally addressed via the adoption of the ADA in 1990. The ADA addresses both employer-sponsored insurance benefits in Title I and individual insurance as part of the public accommodation provision in Title III. ${ }^{24}$ Yet, from the outset, the ADA has been sharply constrained in its ability to challenge health insurance practices that potentially discriminate based on disability. There are several reasons for its inaptitude having to do both with the text of the legislation itself and with the courts' construction of that language. For example, the courts have a tendency to construe many provisions in the ADA narrowly, such as in defining what constitutes a disability under the meaning of the statute. ${ }^{25}$ Furthermore, courts have frequently read both the ADA and the Rehab Act as reaching only challenges about the denial of access to benefits, and not permitting challenges about how the content of those benefits unfairly discriminates. ${ }^{26}$

20 " $\{\mathrm{A}\}$ group health plan, and a health insurance issuer offering group health insurance coverage in connection with a group health plan, may not establish rules for eligibility (including continued eligibility) of any individual to enroll under the terms of the plan based on any of the following health status-related factors in relation to the individual or a dependent of the individual: (A) Health status; (B) Medical condition (including both physical and mental illnesses); (C) Claims experience; (D) Receipt of health care; (E) Medical history; (F) Genetic information; (G) Evidence of insurability (including conditions arising out of acts of domestic violence); (H) Disability." 29 U.S.C. $§ 1182$.

21 See (Bagenstos 2004) ("In its current form, our health insurance system affirmatively disserves the interest of people with disabilities in moving into the workforce ... private insurance ... fails to cover the services people with disabilities most need for independence and health. And public insurance is saddled with requirements that lock people with disabilities out of the workforce.").

22 While insurance is a driver of this issue, so are barriers that disabled people face in delivery of medical care, including physician bias and problems with the built structure. For more on how these barriers can affect disabled people's access to healthcare, see (Pendo 2008).

23 Rehabilitation Act of 1973 § 504, 29 U.S.C. $\$ 794$ (2012).

24 Americans with Disabilities Act of 1990, 42 U.S.C. §§ 12101-12213 (2012). Title III extends to insurance offices as places of public accommodation.

25 In part, the ADA amendments act sought to broaden the definition of what constitutes a disability within the meaning of the statute. See generally (Long 2008).

26 The access/content distinction poses a serious limitation to any effort to improve health benefits for the disabled via the ADA or the Rehab Act. The access/content distinction is not a textual requirement of the ADA or Rehab Act, instead it is a doctrine developed by the courts, in cases like Alexander v. Choate, 469 U.S. 287, 304 (1985). As Bagenstos notes, "[t] $\mathrm{t}$ hese doctrines categorically exclude certain classes of accommodation from the purview of [disability law] - even if the requested accommodations could be provided reasonably and without undue hardship." (Bagenstos 2009, pp. 55, 71). By categorically refusing to consider discrimination in benefits, the courts, in interpreting the law in this manner, overlook the fact that "treating the disabled and nondisabled exactly alike will not result in the same benefits for the two groups; otherwise, there would be no need for a Rehabilitation Act or an ADA." (Abbe 1999, p. 1202). A number of scholars have attempted to argue for different interpretations of Choate. For example, see (Francis and Silvers 2008, pp. 452-53) (arguing that the access/content reading is too restrictive and that the standard of "meaningful access" can enable a discussion of 
Another serious limitation and the focus of this paper is what is known as the insurance safe harbor. ${ }^{27}$ The safe harbor insulates the underwriting of risks by insurers and by entities that administer the benefit plans from ADA challenges; for example, employers that offer health benefits remain protected from ADA legal challenges. ${ }^{28}$ The insurance safe harbor contains one exception, which is that the underwriting cannot be used as a "subterfuge" to permit discrimination. ${ }^{29}$ Take the example of an HIV positive patient with a plan that caps annual expenses for treatments that are related to HIV-if the insurer could prove that this cap was economically justified, that the services required for this HIV patient were significantly higher than those for other groups, then the ADA could overlook this annual cap, even though the disabled person is being treated differently and disadvantageously than a nondisabled person on the basis of his disability.

Notably, the insurance safe harbor is somewhat unique to the ADA. ${ }^{30}$ Title VII's provisions that prohibit race and sex based classifications in employment benefits do not forgive such underwriting. ${ }^{31}$ Nor do the protections from health insurance discrimination found in the Pregnancy Discrimination $\mathrm{Act}^{32}$ or the Genetic Information Nondiscrimination Act. ${ }^{33}$ One exception that does also permit price-based distinctions is the Age Discrimination in Employment Act of 1967 (ADEA), which allows for health plans to charge older employees more, in part to avoid discouraging employers from hiring older employees. ${ }^{34}$

In explicitly permitting legitimate actuarial practices, the ADA suggests that it is justifiable to set economically rational limitations on the benefits of the disabled, even if it disadvantages them. ${ }^{35}$ While the safe harbor is only one limitation in the ADA's ability to fight insurance discrimination, it is significant, particularly because of its very public and textual embrace of inequality for the disabled in this specific context. It sanctions discrimination in the very law that is meant to produce equality. ${ }^{36}$

The many changes that the ACA makes to our healthcare financing system appear, at first blush, to decrease the importance of this limitation of the ADA. The ACA overrides the insurance safe harbor, in practice, by frequently limiting or outright prohibiting the use of actuarial calculations, including for the disabled or for those with poor health statuses. For example, the ACA installs community

substantive access). This work is added to in other scholarship by Professors Francis and Silvers (Francis and Silvers 2017). For an argument that Choate and the access/content distinction may have been overturned by the ACA, see (Blake 2017).

2742 U.S.C. § 12201(c) (2012). “This Act shall not be construed to prohibit or restrict (1) an insurer, hospital or medical service company, health maintenance organization, or any agent, or entity that administers benefit plans, or similar organizations from underwriting risks, classifying risks, or administering such risks that are based on or not inconsistent with State law; or (2) a person or organization covered by this chapter from establishing, sponsoring, observing or administering the terms of a bona fide benefit plan that are based on underwriting risks, classifying risks, or administering such risks that are based on or not inconsistent with State law; or (3) a person or organization covered by this chapter from establishing, sponsoring, 28 Id. observing or administering the terms of a bona fide benefit plan that is not subject to State laws that regulate insurance."

29 Id.

30 See (Crossley 2000).

31 Id., characterizing the ADA's protections as "thin" when compared to these other statutes.

32 Pregnancy Discrimination Act of 1978, 42 U.S.C. $\$ \S 2000$ e.

33 Genetic Information Nondiscrimination Act of 2008, § 101-6. Also see (Roberts 2011), explaining how GINA was designed to promote accessibility to genetic testing and to allay fears in the public mind that insurers and employers would use genetic information to discriminate.

3429 C.F.R. § 1625.10. The ADEA permits lesser benefits for older workers to the extent that it offsets the increased cost of those benefits for that age group. Anything more than this is considered a subterfuge meant to evade the broader purpose the ADEA, of inhibiting age-based discrimination in the workplace.

35 For an overview of the legislative history behind the insurance safe harbor, see (Manning 2000).

36 Some scholars may argue that the safe harbor is less of a barrier to access for the disabled than other issues in the ADA, like the access content distinction. (Bagenstos 2004, p. 39) ("What is striking, however, is that the cases that have rejected ADA challenges to condition- and treatment-specific exclusions and caps have not, for the most part, relied on the safe harbor provision ... The cases have consistently rejected challenges to disability-related caps or exclusions, and they have typically done so on access/content grounds" citing Doe v. Mut. of Omaha Ins. Co., 179 F.3d 557, 558 (7th Cir. 1999), in which Judge Posner permitted a cap on annual HIV benefits to stand based on the access/content distinction rather than the safe harbor.) Indeed, courts infrequently rely on the safe harbor in dismissing suits against insurers. In this paper, I do not suggest that the safe harbor is the most important limitation of the law, but it certainly poses its own harms. At any point it could be used by courts to reduce services for the disabled and, in addition, it reflects a harmful approval of differential treatment of the disabled in healthcare by Congress that no longer reflects current law or policy goals. 
rating into individual and small group insurance plans, meaning that people cannot be charged higher premiums regardless of health status, disability, gender, and many other characteristics. ${ }^{37}$ Insurers can no longer use actuarial risks to decline insurance coverage, ${ }^{38}$ to terminate it, ${ }^{39}$ or to impose lifetime or annual caps on benefits. ${ }^{40}$ While many benefits remain uncovered (especially those pertinent to the disabled community), insurers must cover at least a baseline level of health benefits for all covered parties. ${ }^{41}$ Moreover, Section 1557 of the ADA extends Rehab Act protections to private insurers, physicians, and other healthcare entities that are accepting federal money (for example via federally-subsidized insurance premiums). ${ }^{42}$ The Rehab Act does not contain an insurance safe harbor, so some litigants may be able to avoid that hurdle by claiming discrimination under Section 1557 and the Rehab Act rather than the ADA. ${ }^{43}$ However, it is unclear how a court would handle this approach, and, moreover, this approach could no longer be available were the ACA or Section 1557 to ever be repealed.

The ACA has moved the ball forward significantly for people with disabilities, in insurance market reforms that are designed to make health insurance more affordable for those with healthcare needs and also in expanding Medicaid to allow for greater insurance coverage population-wide. ${ }^{44}$ Yet, as the next section argues, the possible harms of the ADA's insurance safe harbor are not fully neutralized by the ACA and there are both practical and principled reasons to amend the ADA to remove the insurance safe harbor.

\section{Ongoing Harms Caused by the ADA's Insurance Safe Harbor}

This section offers several rationales for why we ought to amend the ADA to remove the insurance safe harbor, arguing that it represents significant ongoing harms, even after the ACA's changes to the insurance market.

\subsection{Practical Harms of the ADA's Insurance Safe Harbor}

While the ACA eliminates most disability-based discriminatory practices in health insurance, it is first and foremost not a disability rights law, but a health reform law meant to improve the system for many different populations and from many different vantage points (greater access, more affordability, better quality, etc.). ${ }^{45}$ Components of the ACA might well be disadvantageous to the disabled because the law was not designed with this group's needs in mind. The ADA is an important tool to challenge any possible problems within the ACA that may hurt the disabled. Yet, the ADA is a poor tool for doing this because of the safe harbor.

37 Patient Protection and Affordable Care Act § 270142 U.S.C. § 300gg (2012). Certain exceptions to community rating exist including tobacco use, age, and geography. These may serve to disadvantage disabled people in some instances. See (Liber et al. 2015).

38 PPACA $\S 2702,42$ U.S.C. $\S 300 \mathrm{gg}-1$.

39 PPACA § 2703,42 U.S.C. $\$ 300 \mathrm{gg}-2$.

40 PPACA § 2711,42 U.S.C. § $300 \mathrm{gg}-11$.

41 Known as the essential health benefits provision, or EHB, insurers must cover some services in the following ten categories: ambulatory patient services (outpatient care), mental health and substance use disorder services, prescription drugs, rehabilitative/habilitative services, emergency care, hospitalization, maternity/pregnancy care, laboratory services, preventive and wellness services, and pediatric care including oral and vision. Patient Protection and Affordable Care Act § 1302(b)(1), 42 U.S.C. § 18022 (2012).

42 Patient Protection and Affordable Care Act, 42 U.S.C. § 18116(a) (2012). Section 1557 prohibits discrimination on the basis of age, race, gender, or disability by "any health program or activity, any part of which is receiving Federal financial assistance $\ldots$, or under any program or activity that is administered by an Executive Agency or any entity established under [Title I of the Act or its amendments]."

43 Cite to Elizabeth Pendo, speaking presentation?

44 See (Musumeci 2014).

45 For example, the ACA also intended to reduce health status discrimination in the private market and to expand access for a variety of groups who were disparately uninsured, like young people and low income people. 
Take, for example, the ACA's provisions governing employee wellness plans. ${ }^{46}$ Health contingent wellness plans permit employers to gather biometric and other data on their employees and to financially penalize those employees whose biometric scores are not within a designated range. ${ }^{47}$ While these plans are viewed by some as an important way to help control healthcare costs and incentivize better health in employees, many challenge the efficacy of wellness plans in saving money or improving health. ${ }^{48}$ Either way, the plans are widely recognized for disadvantaging the disabled who, because of their disabilities, may not be able to attain the biometric scores that their employers wish them to have. ${ }^{49}$ In this way, wellness plans may simply shift healthcare expenses off of some employees and the employer and onto disabled employees in particular.

In one case, a disabled worker in partnership with the Equal Employment Opportunity Commission (EEOC) alleged that an employee wellness plan's mandatory medical examinations unfairly discriminated on the basis of disability. ${ }^{50}$ The employer, a lighting company, alleged that the ADA safe harbor immunized their employer wellness plans from an ADA challenge. ${ }^{51}$ While this litigation was pending, the EEOC issued a regulation stating that wellness plans were not within the purview of the ADA's insurance safe harbor. ${ }^{52}$ The court held that the EEOC's regulations were proper and within the EEOC's authority. They also held that the safe harbor did not apply to the wellness plan, irrespective of the EEOC regulation, because the wellness plan was independent from the insurer and did not function to classify or underwrite risk..$^{53}$ While this is a win for disability advocates, legislation in the form of House Bill 1313 has been introduced that seeks to protect and promote wellness plans. ${ }^{54}$ This proposed legislation would explicitly overturn the EEOC regulations and permit the application of the insurance safe harbor to wellness plans. ${ }^{55}$ Thus, it would allow for discrimination against the disabled so long as it was actuarially based and not a subterfuge for discrimination. While the court and the EEOC did not think that the safe harbor should apply to wellness plans, there is no guarantee that this position would not be changed in the future with a different judge, different agency leadership, or both if new law were in placed prompted by House Bill 1313. As this legislation suggests, even in the face of significant changes to the way we regulate and finance healthcare via the ACA, the ADA's insurance safe harbor remains a go-to method to single out and treat the disabled differently within the ACA's regulatory framework.

There is another clear reason not to rely only on the ACA (or Section 1557) to secure and sustain these important rights for the disabled, however the ACA is, and is likely to remain under, political threat. ${ }^{56}$ If provisions in the ACA like the essential health benefit provision or the protections for people with preexisting conditions are rolled back, the disabled community could find themselves back where they started, facing significant challenges in getting affordable insurance that covers their healthcare needs. Of course, the disabled would not be the only community harmed by an ACA repeal. But, while some other groups could turn to antidiscrimination protections for help, the disabled community would again face the ADA and its limitations to challenging insurance discrimination. ${ }^{57}$

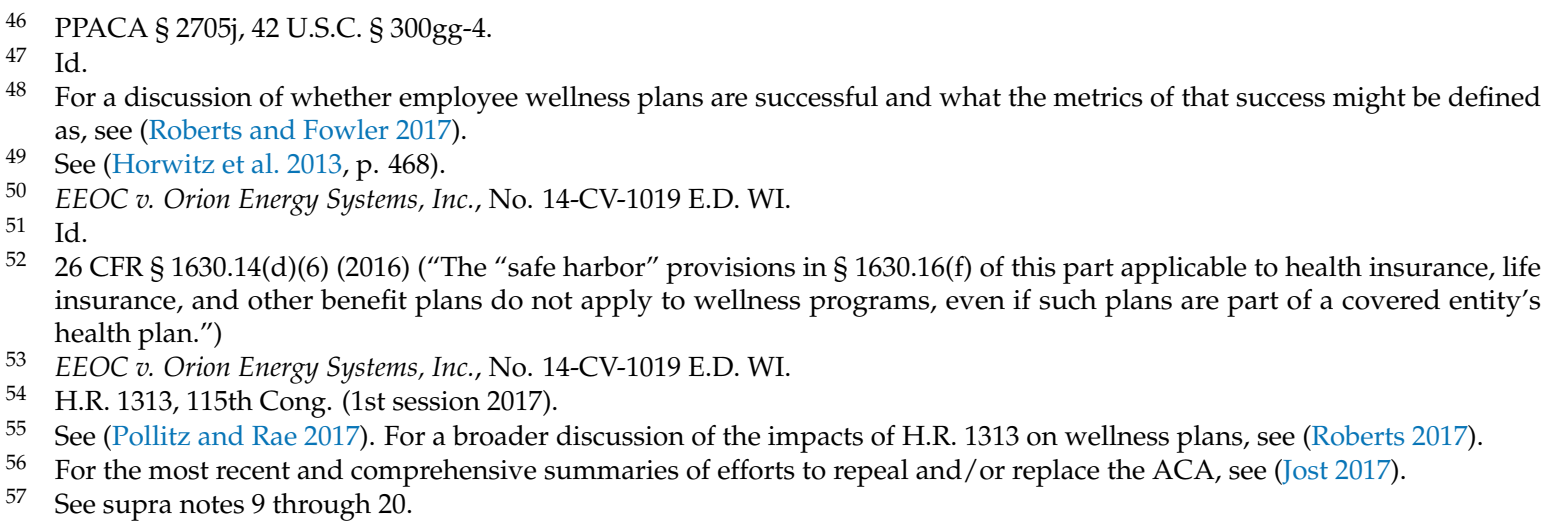




\subsection{Principal Harms of the ADA's Insurance Safe Harbor}

On a more theoretical level, the safe harbor appears to contradict a public sea change in the ways in which we finance healthcare since the adoption of the ACA. While many elements of the ACA may be disfavored and up for debate, public support seems to favor those provisions that ban discrimination on the basis of health status or preexisting conditions. ${ }^{58}$ This merits discussion about whether the time is ripe to reconsider the ADA safe harbor in light of whether it supports modern values in healthcare, and whether the safe harbor reflect fair and true differences about the way we finance healthcare for the disabled, or rather whether it may be a byproduct of larger societal stigma against the disabled as a class.

Stigma is the sociological exploration of how we as a society construct and devalue certain social identities. ${ }^{59}$ Spoiled or stigmatized identities can occur in any society and require contextualization with respect to time and place. ${ }^{60}$ For example, obesity has long been privileged in some communities, both current and past, as a sign of wealth and good health, while it is stigmatized in modern America as unhealthy and unattractive The social constructs we use to make meaning of peoples' identities lead to in- and out-crowds, influencing peoples' opportunities, and social capital. ${ }^{61}$ Stigma has been linked to widespread population health inequality. ${ }^{62}$ Link and Phelan describe in detail the process that must occur in order for a group to be stigmatized. ${ }^{63}$ First, the public must observe and label human differences and give them meaning. ${ }^{64}$ Second, society attaches stereotypes to those labels, ascribing these attributes to the whole. ${ }^{65}$ Third, an us vs them tension is created, whereby people focus on how they are different than others, wishing to differentiate and to be kept apart from the stigmatized group. ${ }^{66}$ Fourth, the stigmatized group experiences various forms of discrimination because of their lowered social status. ${ }^{67}$ Lastly, power is exerted over the stigmatized group to ensure that they are kept in lower social standing. ${ }^{6}$

Applying the concept of stigma to the ADA safe harbor can help to begin a dialogue about whether it is motivated by genuine differences in the disabled as a community with respect to health insurance, or whether it may better be characterized as driven in part or whole by artificial limitations we place on the community because of stigma.

\section{Stigma as Applied to the Insurance Safe Harbor}

In order for stigma to be formed, labeling must occur. ${ }^{69}$ The labeling of disabled as different than able bodied is a very clear social phenomenon in healthcare, employment, and may other areas. Congress, in carving out the disabled as a class with the ADA and the Rehab Act, is identifying them as a cohesive group with collective interests.

To label is not necessarily problematic. We frequently label different groups, black or white, male or female, young or old. These categorizations may be oversimplified though. ${ }^{70}$ Disabled people, for instance, can exhibit a range of levels of ability across a group, and individuals can exhibit able-bodied traits in some instances, while not in others. Likewise, skin color is marked by a host of

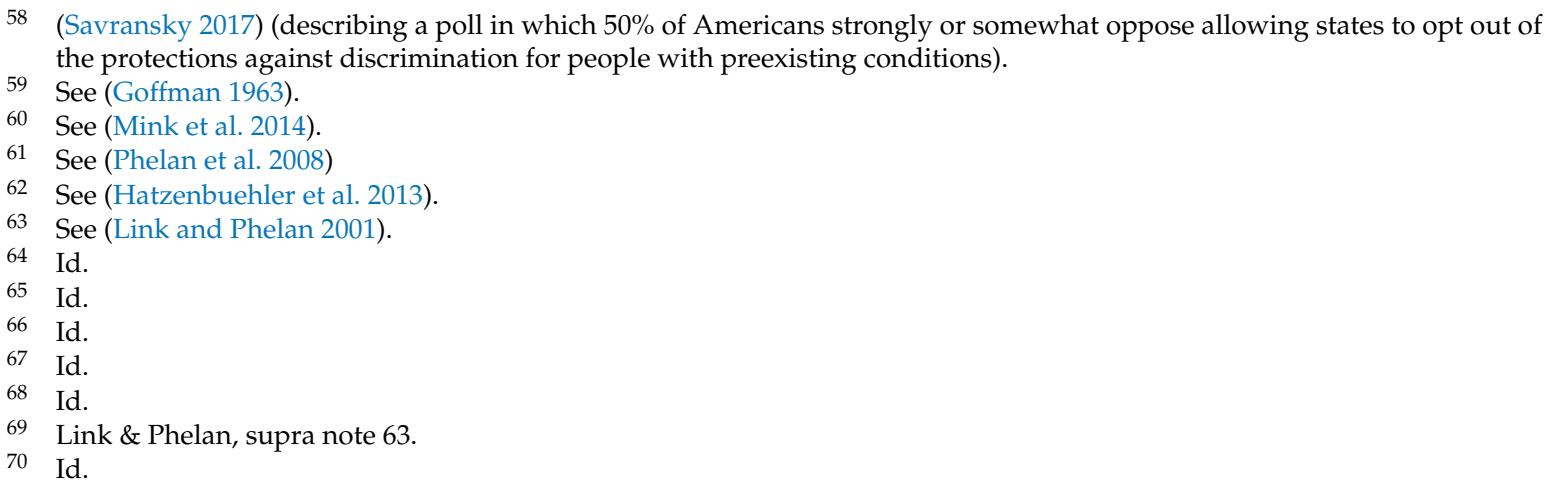


variations, but we simply label it as black or white. As Link and Phelan observe, "once differences are identified and labeled, they are typically taken for granted as being just the way things are- there are black people and white people, blind people and sighted people ... The taken-for-granted nature of these categorizations is one of the reasons that designations like these carry such weight." ${ }^{\prime 71}$ Thus, while disability may not matter in a given context, we may be programmed to recognize the distinction anyway and assume it has meaning.

While labeling may not be problematic, it is negative loading or the stereotyping of certain attributes to that label that create problems for the labelled groups. ${ }^{72}$ The second component of stigmatization, society attributes harmful stereotypes or undesirable characteristics to the group. ${ }^{73}$ Such stereotypes about disabled peoples' health are well recorded. Disability is often linked in the public mind to sickness and inability. The medical model of disability long stressed the idea that disability is a problem that must be fixed, typically through medical intervention. ${ }^{74}$ Only when the social model of disability was advocated for did disability begin to be viewed not as an inherent problem of the disabled person, but instead a problem of society's treatment of that person. ${ }^{75}$ A social model looks to how we build our society to explain disability, not to the disabled person. For example, a building without a ramp does not show that a person in a wheelchair is sick or feeble. Instead, it shows that society did not think about wheelchairs when it built its entrance. Thus, an arbitrary social decision created the disability. With better design, the disability, the label, and perhaps even the stereotype, could disappear.

In the case of the insurance safe harbor, could our harmful stereotyping of the disabled as the sick and less capable lead to a general acceptance of underwriting their illnesses? It is possible, though more exploration is warranted. Certainly, it is telling that the insurance safe harbor does not exist in most other antidiscrimination laws that deal with health insurance and protect on the basis of pregnancy, genetics, or race, for example. ${ }^{76}$ The insurance safe harbor could reflect a presumption that the disabled are less healthy and are more burdensome to insurers, or that disability is so frequently intertwined with insurability that allowing legal challenges would be impractical, bogging the courts and agencies down with too many challenges. ${ }^{77}$

By eliminating the opportunity to legally challenge underwriting on the basis of disability except when it is a subterfuge of disability discrimination, the safe harbor puts burdens on the disabled to prove the underwriting is wrong or unfair, and it largely paints all disabled with the same broad brush of likely being costly to the system. ${ }^{78}$ But more importantly, by eliminating the opportunity for legal challenge, we have no way of knowing what such suits would look like, what their impact on healthcare financing would be, or their frequency; ultimately, we have no way of knowing whether they would be burdensome or not.

debate over medical and social models of disability is critical and far beyond the scope of this paper. For further discussion of these key issues see (Oliver 2013) (describing, as a thought leader in the social disability movement, the movement away from the medical model and its attending harms, while also exploring some limits of the social model). Also see (Stein 2007) (arguing for a need to focus on human worth rather than ability). See generally (Shakespeare 2017, p.195).

75 Shakespeare, supra note 74.

76 See supra notes $28-32$.

77 This was certainly a concern emphasized by the Choate court when it denied that cuts to covered Medicaid hospital stays was a form of discrimination against the disabled. "Because the handicapped typically are not similarly situated to the nonhandicapped, respondents' position would in essence require each recipient of federal funds first to evaluate the effect on the handicapped of every proposed action that might touch the interests of the handicapped, and then to consider alternatives for achieving the same objectives with less severe disadvantage to the handicapped. The formalization and policing of this process could lead to a wholly unwieldy administrative and adjudicative burden." Alexander v. Choate, 469 U.S. 287, 304 (1985).

78 This burden is particularly challenging, given that the proof of whether a given practice is actuarially fair would lie in the hands of the insurer, not the disabled insured. 
In Link \& Phelan's third step of the stigma construct, "us vs. them" scenarios play out as members of society seek to differentiate and separate themselves from the stigmatized. ${ }^{79}$ In this step, "the linking of labels to undesirable attributes become the rationale for believing that negatively labeled persons are fundamentally different from those who don't share the label." 80 This type of tension is somewhat inherent to insurance. In a seminal article, Deborah Stone describes this chronic challenge in healthcare financing as a tension between two competing visions. ${ }^{81}$ Those who assume that they will have minimal healthcare costs are unwilling to pool others' risks, instead preferring to pay a premium that is as closely aligned to their expenses as possible. ${ }^{82}$ Under a social solidarity model, everybody is viewed as being equally responsible for shouldering the expenses of the sick, whomever they are, in part because of recognition that each and every one of us could be in need of such mutual aid one day. ${ }^{83}$ As Crossley observes, the ADA's insurance safe harbor represents "a distinct tilt toward an actuarial fairness approach to health insurance", in which everyone is responsible for paying their own way, rather than a social solidarity approach, where the public at large shares the healthcare burdens of the disabled. ${ }^{84}$

This delineation in health insurance reflects a clear battle between disabled and nondisabled from the perspective of the ADA. It reflects an unwillingness to shoulder the financial costs of healthcare expenses for the disabled. While the ADA at large embraces a vision of equal rights and privileges for the disabled in society, it stops short of being willing to finance it in one very important realm, that of healthcare. ${ }^{85}$ The reality is that no one can predict accurately their own risk of healthcare consumption in a given year, nor is it easy to gauge one's own annual expenses when compared to the annual expenses of individuals in other relevant social groups like "reproductive aged woman" or "person with history of cancer." In embracing the insurance safe harbor, the adopters of the ADA were embracing an insurance pool in which the risks of the disabled were set aside and left without mutual aid. ${ }^{86}$

In the fourth part of the stigma process, the labeled individuals experience status loss and discrimination, driving unequal outcomes. ${ }^{87}$ Here, the evidence would be that the labeling, stereotyping, and pitting of interests of the disabled versus others is what led to the insurance safe harbor and its justification. The insurance safe harbor can be seen as an inherent and legally sanctioned assumption that actuarial price matters in disability, and it indeed matters more than in other social categories, like race or gender. The safe harbor's discriminatory effects could be seen in how poorly insurance is designed for the disabled. How it often does not cover the necessary benefits, and how the disable shoulder high out of pocket costs.

Lastly, stigma is underscored by examining where the locus of power lies. ${ }^{88}$ Link and Phelan use the example of a lawyer. ${ }^{89}$ While certain populations may dislike and highly disrespect lawyers, lawyers occupy powerful places in society and so they cannot be fully stigmatized. ${ }^{90}$ Link and Phelan advise us to consider the availability of power in certain social groups in deciding whether they are

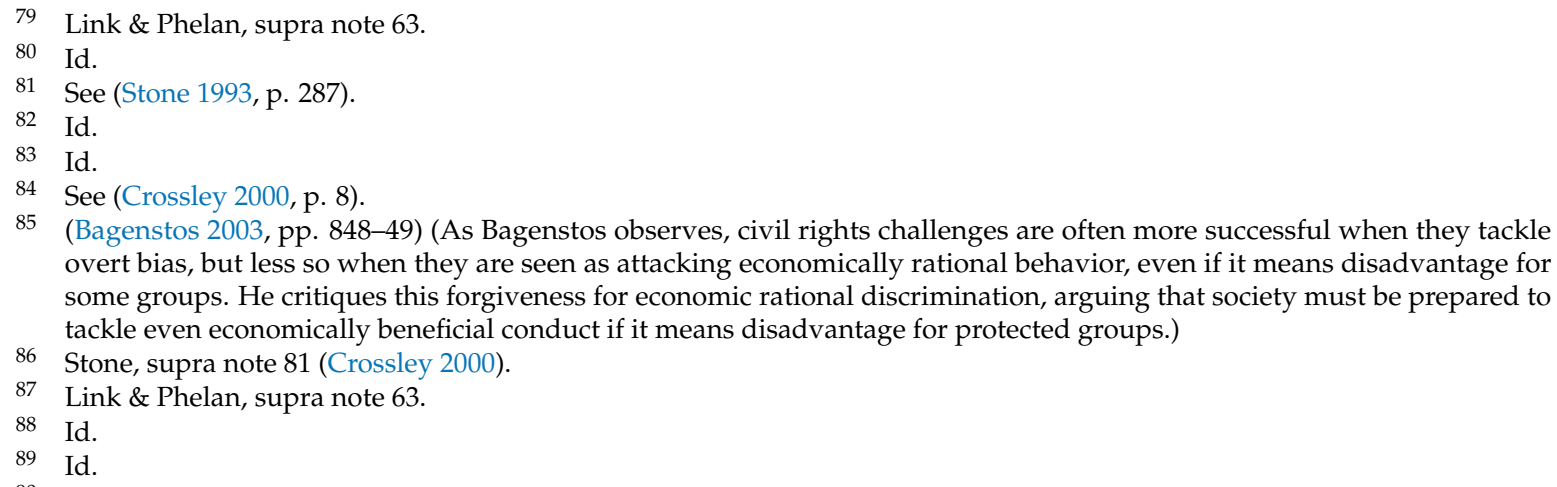
overt bias, but less so when they are seen as attacking economically rational behavior, even if it means disadvantage for some groups. He critiques this forgiveness for economic rational discrimination, arguing that society must be prepared to tackle even economically beneficial conduct if it means disadvantage for protected groups.) 
being stigmatized. ${ }^{91}$ In the context of health insurance, we frequently see differing treatment for those groups who are also viewed as vulnerable in other contexts: the disabled, the poor, the sick. ${ }^{92}$ Certainly, by eliminating the right to legally challenge the insurer, the ADA diminishes the power that it otherwise gives to the disabled to challenge discriminatory practices.

It merits further exploration to determine whether the insurance safe harbor could be informed by broader stigmatization of the disabled, or whether other laws and policies in healthcare and other contexts may also reflect such stigma. But it is worth observing, either way, that sustaining the safe harbor in the face of sweeping change to the healthcare finance system could serve as its own form of stigma for the disabled. While underwriting based on health status is now widely rejected by the ACA (and seemingly the public mind), including on the basis of disability, we still see a law on the books that supports this practice for the disable. This could be used by those who would seek to return to the old ways and single out the disabled again as a harmful example of how the disabled are different or "other" with respect to healthcare coverage.

\section{The Future of the ADA's Insurance Safe Harbor}

To the extent that the ADA's insurance safe harbor remains harmful even after the ACA, what ought to be done about it?

One proposal would be to attempt to repeal this provision of the ADA through Congress. This may be an unlikely proposal, given the unusual degree of partisanship and gridlock in Washington. However, disability rights laws have often enjoyed support across both aisles. For example, the ADA was passed with broad bipartisan support. ${ }^{93}$ More so, the public increasingly embraces a vision of social solidarity, where access to affordable health insurance is not influenced by health status or disability, as seen in the many debates surrounding repealing and replacing the ACA. To a certain extent, removing the safe harbor is only underscoring what other laws like the ACA have already decided for us, that disability based discrimination in healthcare in unlawful and inappropriate.

Another valid inquiry may be to examine to what extent the ADA's insurance safe harbor has been superseded by the ACA, both its general provisions and more specifically in Section 1557 of the ACA. One possible argument would that the ADA's insurance safe harbor conflicts with certain provisions of the ACA and Section 1557, and that these latter provisions ought to be considered as the rule of law. Certainly, Congress has not explicitly rejected the ADA's insurance safe harbor and repeal by implication is disfavored. ${ }^{94}$ However, this doctrine can be overcome with enough evidence. When two statutes conflict, courts will apply the general-specific canon, asking first whether one statue is more specific than the other. ${ }^{95}$ If it is, then the more specific statute controls over the general statute. ${ }^{96}$ If the two statutes are equally general or equally specific, then the more recent statute ought to govern. ${ }^{97}$ It is not immediately clear, which would be viewed by a court as more specific. The ADA addresses disability concerns broadly with healthcare being only one part, whereas the ACA addresses healthcare, broadly, with disability being only one part. Section 1557 may be a superior statute to compare with the ADA. By extending the Rehab Act to regulate private insurers, Congress may arguably have intended to reject the insurance safe harbor as this provision is not a part of Rehab

91 Id.

92 See (Crossley 2000).

93 The Senate passed the ADA with a final vote of 76-8 while the House passed it with a final vote of $377 / 28$. Govtrack, Americans with Disabilities Act of 1990 (Govtrack n.d.).

94 "[R]epeals by implication are not favored ... and will not be found unless an intent to repeal is clear and manifest." (Eig 2011).

95 Id. First, "courts will try to harmonize the two so that both can be given effect. A court "must read [two allegedly conflicting] statutes to give effect to each if [it] can do so while preserving their sense and purpose." Only if provisions of two different 96 Id. federal statutes are "irreconcilably conflicting," will the courts then consider which statute ought to prevail.

97 Id. 
Act. ${ }^{98}$ Arguably, this could mean an effort by Congress via Section 1557 of the ACA to embrace a more social solidarity viewpoint in healthcare financing for the disabled, which is certainly supported by the wider goals of the ACA, as well. Certainly, the EEOC in drafting its guidance on wellness plans asserted a similar argument regarding the safe harbor-that the ADA safe harbor may have been superseded by other future laws that moved away from actuarial fairness. ${ }^{99}$ Alternatively, to the extent that neither law seems more specific or more general, then the ACA and Section 1557 would win out as the newer law - and the insurance safe harbor would still be rejected. ${ }^{100}$ In any event, these arguments could be weakened if the ACA or parts of it were to be repealed. It would be important to pay attention to what aspects of the ACA remained, and whether arguments could still be made that parts of law, whether Section 1557 or otherwise, conflict with the ADA safe harbor provision.

Further research is warranted to explore the legal relevance of the safe harbor in the face of ACA, as well as whether ADA modifications of the insurance safe harbor are necessary and, if so, what mechanisms, legal or political, might be the best approach. Additionally, it is worthwhile to consider the larger the consequences of such a modification. Would removing the insurance safe harbor make insurers less likely to participate in the insurance pool? Alternatively, laws like the ADEA put an insurance safe harbor in place, in part, to encourage employers to hire older workers and to not be deterred by any added burden they might contribute to employer health plans. A concern of repealing the ADA's insurance safe harbor could be that it might discourage employers from hiring disabled workers as an alternative means of avoiding their healthcare expenses. While in both instances the ADEA and ADA would be available to challenge discriminatory hiring practices, this could still prove problematic as both of the laws are sometimes viewed as limited in fully leveling the playing field in employment. These and other possible problems would need to considered and weighed in deciding whether to move forward with efforts to repeal or modify the insurance safe harbor.

Ending the insurance safe harbor could be a way to reconcile the ADA with the ACA, embrace public support for antidiscrimination in healthcare financing, and fight stigmatizing notions that the disabled are somehow less worthy of mutual aid in healthcare. It is worth further consideration as to whether repeal or modification is possible, and what the ramifications of such a repeal might be.

Acknowledgments: The author would like to thank the Arthur B. Hodges Summer Research Grant program for providing research support, Elizabeth Pendo for guest-editing this important special issue, and the staff and editors at Laws for their support.

Conflicts of Interest: The author declares no conflict of interest.

\section{References}

Abbe, Alexander. 1999. "Meaningful Access" to Health Care and the Remedies Available to Medicaid Managed Care Recipients under the ADA and the Rehabilitation Act. University of Pennsylvania Law Review 147: 1161-203. [CrossRef]

Bagenstos, Samuel R. 2003. "Rational Discrimination," Accommodation, and the Politics of (Disability) Civil Rights Law. Virginia Law Review 89: 825-923. [CrossRef]

Bagenstos, Samuel R. 2004. The Future of Disability Law. The Yale Law Journal 114: 1-84. [CrossRef] Bagenstos, Samuel R. 2009. Law and the Contradictions of the Disability Rights Movement. New Haven: Yale University Press. Blake, Valarie K. 2017. Restoring Civil Rights to the Disabled in Health Insurance. Nebraska Law Review 95 : 1071-123.

98 Cite to Elizabeth Pendo, speaking presentation?

99 81 F.R. § 31125. EEOC, for example, argues that HIPAA may have moved away from the insurance safe harbor long before the ACA did. "At the time the ADA was enacted, health plans were allowed to engage in some practices that are no longer permitted today. For example, before HIPAA made the practice illegal in 1996, group health plans were allowed to charge individuals in the plan higher rates based on increased risks associated with their medical conditions. The ADA's safe harbor provision was intended to protect this now unlawful practice..." (emphasis added).

100 Eig, supra note 94. 
Cole, Melissa. 2003. In/Ensuring Disability. Tulane Law Review 77: 873-84.

Crossley, Mary. 2000. Becoming Visible: The ADA's Impact on Health Care for Persons with Disabilities. Alabama Law Review 52: 51-89.

Eig, Larry M. 2011. Statutory Interpretation and Recent Trends, Congressional Research Service. Available online: https:/ / fas.org/sgp/crs/misc/97-589.pdf (accessed on 4 August 2017).

Francis, Leslie Pickering, and Anita Silvers. 2008. Debilitating Alexander v. Choate: “Meaningful Access" to Healthcare for People with Disabilities. Fordham Urban Law Journal 35: 447-77.

Francis, Leslie, and Anita Silvers. 2017. Reading Alexander v. Choate Rightly: Now is the Time. Laws 6: 17. [CrossRef]

Goffman, Erving. 1963. Stigma: Notes on the Management of Spoiled Identity. London: Penguin.

Govtrack. n.d.; Americans with Disabilities Act of 1990. Available online: https:/ /www.govtrack.us/congress / bills/101/s933/details (accessed on 4 August 2017).

Hatzenbuehler, Mark L., Jo C. Phelan, and Bruce G. Link. 2013. Stigma as a Fundamental Cause of Population Health Inequalities. American Journal of Public Health 103: 813-21. [CrossRef] [PubMed]

Horwitz, Jill R., Brenna D. Kelly, and John E. DiNardo. 2013. Wellness Incentives in the Workplace: Cost Savings through Cost Shifting to Unhealthy Workers. Health Affairs 32: 468-76. [CrossRef] [PubMed]

Jost, Timothy. 2017. The Senate's Healthcare Freedom Act. Health Affairs Blog. July 27. Available online: http: / / healthaffairs.org/blog/2017/07/27/the-senates-health-care-freedom-act/ (accessed on 4 August 2017).

Liber, Alex C., Jeffrey M. Drope, Ilana Graetz, Teresa M. Waters, and Cameron M. Kaplan. 2015. Tobacco Surcharges on 2015 Health Insurance Plans Sold in Federally Facilitated Marketplaces: Variations by Age and Geography and Implications for Health Equity. American Journal of Public Health 105: S696-S698. [CrossRef] [PubMed]

Linder, Stephen, Regan Considine, Melinda Davis, Ruth Rowland, and Margaret Spurlock. 2016. The Impact of the Affordable Care Act on People with Disabilities: A 2015 Status Report. Washington: Urban Institute, Available online: http:/ / www.urban.org/research/publication/impact-affordable-care-act-people-disabilities-2015status-report/view / full_report (accessed on 6 August 2017).

Link, Bruce G., and Jo C. Phelan. 2001. Conceptualizing Stigma. Annual Review of Sociology 27: 363-85. [CrossRef]

Long, Alex B. 2008. Introducing the New and Improved Americans with Disabilities Act: Assessing the ADA Amendments Act of 2008. Northwestern University Law Review Colloquy 103: 217-30.

Manning, Jeffrey S. 2000. Are Insurance Companies Liable under the Americans with Disabilities Act. California Law Review 88: 607-52. [CrossRef] [PubMed]

Miller, Nancy A., Adele Kirk, Michael J. Kaiser, and Lukas Glos. 2014. The Relation between Health Insurance and Health Care Disparities among Adults with Disabilities. American Journal of Public Health 104: e85-e93. [CrossRef] [PubMed]

Mink, Michael D., Lisa L. Lindley, and Ali A. Weinstein. 2014. Stress, Stigma, and Sexual Minority Status: The Intersectional Ecology Model of LGBTQ Health. Journal of Gay E Lesbian Social Services 26: 502-21.

Musumeci, MaryBeth. 2014. The Affordable Care Act's Impact on Medicaid Eligibility, Enrollment, and Benefits for People with Disabilities. Kaiser Family Foundation, April 8. Available online: http:/ / www.kff.org/health-reform/issue-brief/the-affordable-care-acts-impact-on-medicaid-eligibilityenrollment-and-benefits-for-people-with-disabilities / (accessed on 2 August 2017).

Oliver, Michael. 2013. The Social Model of Disability: Thirty Years On. Disability \& Society 28: 1024. [CrossRef]

Pendo, Elizabeth. 2008. Disability, Equipment Barriers, and Women's Health: Using the ADA to Provide Meaningful Access. SLU Journal of Health Law \& Policy 2: 15-56.

Phelan, Jo C., Bruce G. Link, and John V. Dovidio. 2008. Stigma and Prejudice: One Animal or Two? Social Science $\mathcal{E}$ Medicine 67: 358-67.

Pollitz, Karen, and Matthew Rae. 2017. Changing Rules for Workplace Wellness Programs: Implications for Sensitive Health Conditions. Kaiser Family Foundation, April 7. Available online: http:/ / www.kff.org/private-insurance/ issue-brief/changing-rules-for-workplace-wellness-programs-implications-for-sensitive-health-conditions / (accessed on 12 August 2017).

Roberts, Jessica L. 2011. The Genetic Information Nondiscrimination Act as an Antidiscrimination Law. Notre Dame Law Review 86: 597-648.

Roberts, Jessica L. 2012a. "Healthism": A Critique of the Antidiscrimination Approach to Health Insurance and Health-Care Reform. University of Illinois Law Review 1159: 1166.

Roberts, Jessica L. 2012b. Health Law as Disability Rights Law. Minnesota Law Review 97: 1963-2035. [CrossRef] 
Roberts, Jessica L. 2017. Will the Recent Workplace Wellness Bill Really Undermine Employee Health Privacy? Bill of Health. March 15. Available online: http://blogs.harvard.edu/billofhealth/2017/03/15/will-the-recentworkplace-wellness-bill-really-undermine-employee-health-privacy / (accessed on 12 August 2017).

Roberts, Jessica L., and Leah R. Fowler. 2017. How Assuming Autonomy May Undermine Wellness Programs. Health Matrix 27: 101-24.

Rosenbaum, Sara. 2007. The Americans with Disabilities Act in a Health Care Context. In The Future of Disability in America. Edited by Marilyn J. Field and Alan M. Jette. Washington: The National Academies Press.

Savransky, Rebecca. 2017. Poll: Voters want protections for pre-existing conditions. TheHill. May 3. Available online: http:/ / thehill.com/policy/healthcare/331696-poll-voters-want-protections-for-pre-existing-conditions (accessed on 12 August 2017).

Schoen, Cathy, Karen Davis, and Amber Willink. 2017. Medicare Beneficiaries' High Out-of-Pocket Costs: Cost Burdens by Income and Health Status. The Commonwealth Fund. Available online: http:/ /www.commonwealthfund. org/publications/issue-briefs/2017/may/medicare-out-of-pocket-cost-burdens (accessed on 12 August 2017).

Shakespeare, Tom. 2017. The Social Model of Disability. In The Disability Studies Reader, 5th ed. Edited by Lennard J. Davis. Abingdon: Routledge.

Stein, Michael Ashley. 2007. Disability Human Rights. California Law Review 95: 75. [CrossRef]

Stone, Deborah A. 1993. The Struggle for the Soul of Health Insurance. Journal of Health Politics Policy and Law 18: 287-317. [CrossRef]

Wendell, Susan. 2001. Unhealthy Disabled: Treating Chronic Illnesses as Disabilities. Hypatia 16: 17-33. [CrossRef]

(C) 2017 by the author. Licensee MDPI, Basel, Switzerland. This article is an open access article distributed under the terms and conditions of the Creative Commons Attribution (CC BY) license (http://creativecommons.org/licenses/by/4.0/). 